\title{
Image and fractal analysis as a tool for evaluating salinity growth response between two Salicornia europaea populations
}

\author{
S. Cárdenas-Pérez ${ }^{1 *}$, A. Piernik¹, A. Ludwiczak¹, M. Duszyn², A. Szmidt-Jaworska² and J. J. Chanona-Pérez ${ }^{3}$
}

\begin{abstract}
Background: This study describes a promising method for understanding how halophytes adapt to extreme saline conditions and to identify populations with greater resistance. Image and colour analyses have the ability to obtain many image parameters and to discriminate between different aspects in plants, which makes them a suitable tool in combination with genetic analysis to study the plants salt tolerance. To the best of our knowledge, there are no publications about the monitoring of halophytic plants by non-destructive methods for identifying the differences between plants that belong to different maternal salinity environments. The aim is to evaluate the ability of image analysis as a non-destructive method and principal component analysis (PCA) to identify the multiple responses of two S. europaea populations, and to determine which population is most affected by different salinity treatments as a preliminary model of selection.
\end{abstract}

Results: Image analysis was beneficial for detecting the phenotypic variability of two S. europaea populations by morphometric and colour parameters, fractal dimension (FD), projected area (A), shoot height $(H)$, number of branches $(\mathrm{B})$, shoot diameter $(\mathrm{S})$ and colour change $(\Delta \mathrm{E})$. S was found to strongly positively correlate with both proline content and $\Delta \mathrm{E}$, and negatively with chlorophyll content. These results suggest that proline and $\Delta \mathrm{E}$ are strongly linked to plant succulence, while chlorophyll decreases with increased succulence. The negative correlation between FD and hydrogen peroxide (HP) suggests that when the plant is under salt stress, HP content increases in plants causing a reduction in plant complexity and foliage growth. The PCA results indicate that the greater the stress, the more marked the differences. At $400 \mathrm{mM}$ a shorter distance between the factorial scores was observed. Genetic variability analysis provided evidence of the differences between these populations.

Conclusions: Our non-destructive method is beneficial for evaluating the halophyte development under salt stress. $\mathrm{FD}, \mathrm{S}$ and $\triangle \mathrm{E}$ were relevant indicators of plant architecture. PCA provided evidence that anthropogenic saline plants were more tolerant to saline stress. Furthermore, random amplified polymorphic DNA analysis provided a quick method for determining genetic variation patterns between the two populations and provided evidence of genetic differences between them.

Keywords: Halophyte, Fractal architecture, Colour analysis, Morphometry, Genetic analysis

\footnotetext{
* Correspondence: cardenasperez@umk.pl

${ }^{1}$ Chair of Geobotany and Landscape Planning, Faculty of Biological and Veterinary Sciences, Nicolaus Copernicus University, Lwowska 1, 87-100 Toruń, Poland

Full list of author information is available at the end of the article
}

C C The Author(s). 2020 Open Access This article is licensed under a Creative Commons Attribution 4.0 International License, which permits use, sharing, adaptation, distribution and reproduction in any medium or format, as long as you give appropriate credit to the original author(s) and the source, provide a link to the Creative Commons licence, and indicate if changes were made. The images or other third party material in this article are included in the article's Creative Commons licence, unless indicated otherwise in a credit line to the material. If material is not included in the article's Creative Commons licence and your intended use is not permitted by statutory regulation or exceeds the permitted use, you will need to obtain permission directly from the copyright holder. To view a copy of this licence, visit http://creativecommons.org/licenses/by/4.0/ The Creative Commons Public Domain Dedication waiver (http://creativecommons.org/publicdomain/zero/1.0/) applies to the data made available in this article, unless otherwise stated in a credit line to the data. 


\section{Background}

Salinity is nowadays an important environmental problem disturbing plant growth. It has been reported by the [17] that soil salinity has negative impacts on agricultural production, and in particular pollutes natural resources, affecting the balance of ecosystems. Meanwhile, Nelson and Mareida [41] reported in 2001 that more than 10 million ha of irrigated land is excluded from use in production due to high salinity. In this sense, halophytic plants are effective at salt adaptation, as they have a suitable mechanism to grow under salt stress and could be beneficial in the bioremediation of saline soils. The study of halophytes such as Salicornia europaea can help to understand how this type of plant adapts to the extreme conditions of saline areas and to select those that are best adapted. Salicornia belongs to the Chenopodiaceae family and is one of the most salt tolerant genotypes, capable of growing under hyper-saline drainage water. Some studies have reported that its growth and net photosynthetic rate are stimulated rather than inhibited under 100 to $400 \mathrm{mM} \mathrm{NaCl}[6,20,33]$. However, under high extreme salinity conditions, Salicornia experiences modifications in its physiology, cell morphology and biochemistry. The biological effects of salt stress are very different and may include morphological changes such as variation in height, projected area, shoot thickening, plant branching and foliage complexity. They may also include plant colour modification due to a reduced photosynthesis that affects nutrient loss, biomass and hydric balance [40]. Among the few available morphological traits in the genus $S$. europaea, most are extremely variable within species which can probably be attributed to high levels of plasticity or biological adaptations under different environmental conditions [38]. A field experiment performed by Piernik [43] with a Vernier calliper evaluated the shoot height as well as manually identifying the number of shoots, and demonstrated morphological differences between populations growing under different soil salinities. Hairmansis et al. [21] developed a phenotype image analysis as a non-destructive technique for monitoring rice traits under salinity stress. It was concluded that image analysis has the capability to obtain several parameters from - images and to discriminate between the different aspects of salt stress, making it a suitable tool for physiological studies. It was also stated that the image analysis combined with genetic analysis is a useful method for explaining the main processes that influence salinity tolerance in plants. In this context, - recent studies have been looking for simple, accurate and non-destructive methods to evaluate how abiotic stressors affect plants' growth [7, 19, 30, 32]. Regarding plant architecture, fractal dimension has been proven to be a good indicator for analysing plant foliage changes due to salinity. Some studies have analysed plants' irregularity by calculating their fractal dimension [18]. Therefore, this parameter has relevance in the study of plant foliage architecture since it can describe the way that plants physically adapt under abiotic stressors, as well as serving as a predictor of plant biomass $[11,25]$. Plant colour study by image analysis technique has been used in other studies for different purposes. Karcher and Richardson [26] quantified turfgrass colour through image analysis in order to make comparisons between turf sites. Ma et al. [34] applied colour analysis in leaf images by using image preprocessing technique for identifying deficiencies and excess nitrogen content in soybean leaves. However, to the best of our knowledge, no studies have been published using colour analysis as an indicator to evaluate salt stress in plants.

When plants are exposed to high salinity, they induce a reduced stomatal conductance as a strategic mechanism to decrease the net uptake of salt ions and to conserve water in the plant, causing a mesophyll thickening of the shoot [10]. The lower stomatal conductance mechanism leads to the generation of reactive oxygen species (ROS) while at the same time $\mathrm{CO}_{2}$ fixation is reduced, inducing a photosynthetic decrease, which is reflected in changes of the plant pigments due to the reduction in chlorophyll content. The capability of Salicornia to manage salt stress effects can be associated with the scavenging of ROS such as $\mathrm{O}_{2}, \mathrm{H}_{2} \mathrm{O}_{2}$ and $\mathrm{OH}$ [37, 48]. Until now, the majority of studies have tested plant salt adaptation through destructive and slow screening techniques in order to measure different morphological traits. Consequently, these conventional techniques are not suitable to measure in situ dynamic responses in plant growth during salt stress. However, sampling in real-time may be done in field conditions. Recent progress in phenotype image analysis have put emphasis on the non-destructive evaluation of salinity responses of plants over time and this allows the plant biomass to be determined and morphometry to be measured without affecting the whole plant [21, 24]. Currently, there is no publication on the monitoring of halophytic plants by non-destructive methods, especially for identifying the differences between plants that belong to different maternal salinity environments. Therefore, in this study, we aim to evaluate the ability of non-destructive methods such as image and colour analysis, fractal dimension as a quantitative measure of plant development and complexity under salinity, as well as principal component analysis (PCA) to identify the multiple responses of two S. europaea populations from different salinity sites. It is also the aim of this paper to determine which are the most affected by different salinity treatments as a preliminary model of selection from each sample, as it was hypothesized that non-destructive methods are able to 
efficiently determine if S. europaea populations from different sites (natural and anthropogenic) can adapt to salinity differently.

\section{Methods}

Plant materials, growth conditions and salt treatments

Soil samples with $S$. europaea seeds were collected at two sites representing a natural and an industrial saline area in Poland. The first site is supported with natural brine in the health resort of Ciechocinek (C) $\left(52^{\circ} 53^{\prime} \mathrm{N}\right.$, $\left.18^{\circ} 47^{\prime} \mathrm{E}\right)$. Natural salinity in this place is related to salt springs associated with Zechstein salt stratums [44]. The second site is located in the vicinity of a soda factory in the town of Inowrocław-Mątwy (I) $\left(52^{\circ} 48^{\prime} \mathrm{N}, 18^{\circ} 15^{\prime} \mathrm{E}\right)$, with salinity at this site linked to waste from soda production [45, 47]. The first site is characterised by high soil salinity ca $100 \mathrm{dS} / \mathrm{m}(\sim 1000 \mathrm{mM} \mathrm{NaCl})$ [47, 50], with this type of soil salinity described as chloride $\left(\mathrm{Cl}^{-}\right.$: $\mathrm{SO}_{4}{ }^{2-}>2.5$ ) with dominant cations: $\mathrm{Na}>>\mathrm{Ca}>\mathrm{Mg}>\mathrm{K}$ and anions: $\mathrm{Cl}>>\mathrm{SO}_{4}>\mathrm{HCO}_{3}$ [44]. The second site is characterised by a lower salinity of $c a 55 \mathrm{dS} / \mathrm{m}(\sim 550$ $\mathrm{mM} \mathrm{NaCl})[47,50]$. The type of soil salinity is also chloride, with dominancy of cation: $\mathrm{Ca}>\mathrm{Na}>>\mathrm{Mg}>\mathrm{K}$ and anion: $\mathrm{Cl}>>\mathrm{SO}_{4}>\mathrm{HCO}_{3}$ [44]. The distance between $\mathrm{C}$ and I sites is ca $50 \mathrm{~km}$, with both seeming to be fairly isolated from each other. S. europaea seeds were collected in October 2018 and were sterilised with bleach diluted in water (30\%). The seeds were then germinated in the growth chamber in Petri dishes $(\varnothing 7 \mathrm{~cm})$ with a piece of filter paper and $5 \mathrm{ml}$ of distillate water. Once the seeds germinated, they were planted in individual pots (height: $5.3 \mathrm{~cm}$ and diameter: $5.5 \mathrm{~cm}$ ) with a sterile substrate of vermiculite and sand in a ratio of $1: 1$, with an experimental unit per pot and 12 seedlings for each salt treatment. Before planting, each group of 12 pots was located on individual trays lacking drainage, and were saturated at their full capacity with solutions of 0 , 200, 400, 800 and $1000 \mathrm{mM} \mathrm{NaCl}$ (ca $500 \mathrm{ml}$ of solution for 12 pots with the substrate) [46]. The plants were grown in a growth chamber with day/night $\left(25 / 20^{\circ} \mathrm{C}\right)$ photon flux density of $1000 \mathrm{mmol} \mathrm{m}{ }^{2} \mathrm{~s}^{1}$, relative humidity of $50-60 \%$ and a photoperiod of $16 / 8 \mathrm{~h}$ (light/ dark). Seedlings were irrigated through pouring distillate water in the tray for up to 21 days. They were then watered for 30 days with an equal amount of Hoagland's solution every 2 days to ensure homogeneity of salinity and nutrient supply. In total, 120 plants (12 plants $\times 5$ treatments $\times 2$ populations) were cultivated, and, therefore, a complete randomized design with a factorial design $2^{5}$ was used, which included a total 120 samples (12 plants $\times 5$ treatments $\times 2$ populations) with 12 response variables. After 2 months of development, morphometric and colour parameters were estimated in 12 samples while proline, hydrogen peroxide, chlorophyll and carotenoid contents per triplicate were determined (plants were randomly selected). The voucher specimen of the plant material has been deposited in a publicly available herbarium of the Nicolaus Copernicus University in Torun (Index Herbarium code TRN), deposition number not available. (Dr. hab. Agnieszka Piernik, prof NCU undertook the formal identification of plant species and permission to work with the seeds was provided by the Regional Director of Environmental Protection in Bydgoszcz, WPN.6205.159.2014.KLD, WPN.6205.69. 2015.KLD, WPN.6205.44.2016.KLD).

\section{Morphometric and colour analysis}

The size and shape of the plants were characterised by images obtained with a Sony digital camera (13 MP, f/ $2.0,1 / 3^{\prime \prime}, 1.12 \mu \mathrm{m}$, focal length $3.79 \mathrm{~mm}$, with autofocus). After 2 months, samples (the entire plants from the pots) were placed inside a photography light box PULUZ (PU5060, HITSAN, China) equipped with two $30 \mathrm{~W}, 5500 \mathrm{~K}$ integrated LED lights which can soften and reflect light and eliminating glare, while the box wall material works as a lighting diffuser generating homogeneous light on the sample. The camera was located at a distance of $50 \mathrm{~cm}$ from the samples, and the same light and distance conditions were used for capturing the aerial part of the plants. The images were captured in 12 replicates per treatment for the $\mathrm{C}$ and I populations. The images were obtained in RGB and stored in. TIFF format at $4160 \times 3120$ pixels. The images were converted to greyscale and then to binary images by manual segmentation (threshold from 135 to 240) from cropped greyscale images of individual plants. Finally, the shape and size of the plants were obtained from the binary images. All steps of image analysis were performed in Image J. 1.47 software (National Institutes of Health, Bethesda, MD, USA). The projected area (A) was calculated through the number of pixels inside the borderline, while the shoot diameter (S) was determined by the horizontal distance between the two extremes of the middle segment of the shoot. The number of branches (B) was obtained through the total count of branches per individual, and shoot height $(\mathrm{H})$ corresponds to the distance from the base to the apical part. Furthermore, fractal dimension (FD) was used to evaluate the structural shape of growth, and has been used to analyse the complexity of biological samples in many studies [12, 13]. In the present study, FD was evaluated by means of the fractal box count plugin in ImageJ, where higher FD values correspond to complex images. The values range between 1 and 2, with values near 1 indicating a low irregularity, while values near 2 indicate a more irregular or fractal plant structure, meaning that the plants tend to fill bi-dimensional space more effectively. 
The colour change analysis during the salt treatment of plants was carried out according to the methods described by Cárdenas-Pérez et al. [14]. Previous studies concluded that the CIELab space is suitable for the analysis of biological sample colour [35]. The complete plant image (without root) was used to evaluate the colour change of each plant. The values of the pixels on the image of the plant shoots were transformed into CIELab coordinates, $\mathrm{a}^{*}$ (green to red) and $\mathrm{b}^{*}$ (blue to yellow) and L* (luminosity). The conversion plugin was used to convert RGB to CIELab (Illuminant D65). Total colour difference $(\Delta \mathrm{E})$ was calculated with equation 1 :

$$
\Delta E=\sqrt{\left(\Delta L^{*}\right)^{2}+\left(\Delta a^{*}\right)^{2}+\left(\Delta b^{*}\right)^{2}}
$$

where $\Delta \mathrm{L}=\mathrm{L}^{*}-\mathrm{L}_{0}{ }^{*} ; \Delta \mathrm{a}=\mathrm{a}^{*}-\mathrm{a}_{0}{ }^{*}, \Delta \mathrm{b}=\mathrm{b}^{*}-\mathrm{b}_{0}{ }^{*}$; the initial colour parameters correspond to the colour value obtained in the control plants without salt treatment (0 mM).

For the colour comparison among treatments and populations, the $\Delta \mathrm{E}$ parameter was considered a useful descriptive parameter to evaluate the complete difference of colour in each plant. An additional figure file shows a diagram of image analysis carried out herein [see Additional file 1].

\section{Biochemical analysis}

Proline content $(\mathrm{P})$ was measured in plants according to Abraham et al. [1]. Fresh stem material $(500 \mathrm{mg})$ was pulverised on ice and homogenised in a mortar with $3 \%$ aqueous sulfosalicylic acid solution $(5 \mu \mathrm{l} / \mathrm{mg}$ fresh plant material). The homogenate was centrifuged at $18,000 \times$ g, $10 \mathrm{~min}$ at $4{ }^{\circ} \mathrm{C}$, and the supernatant was collected. The reaction mixture was composed of $100 \mu \mathrm{l}$ of $3 \%$ sulfosalicylic acid, $200 \mu \mathrm{l}$ of glacial acetic acid, $200 \mu \mathrm{l}$ of acidic ninhydrin reagent and $100 \mu \mathrm{l}$ of supernatant. Acidic ninhydrin reagent was prepared as described by Bates et al. [8]. P was determined based on the standard curve for proline in the concentration range of 0 to $40 \mu \mathrm{g} / \mathrm{ml}$. The standard curve equation was $y=0.0467 x-0.0734, R^{2}=$ 0.963. $\mathrm{P}$ was expressed in $\mathrm{mg}$ of proline per gram of fresh weight.

Hydrogen peroxide (HP) levels were determined according to the methods described by Velikova et al. [51]. Stem tissues $(500 \mathrm{mg})$ were homogenised with $5 \mathrm{ml}$ trichloroacetic acid $0.1 \%$ (w:v) in an ice bath. The homogenate was centrifuged $\left(12,000 \times \mathrm{g}, 4^{\circ} \mathrm{C}, 15 \mathrm{~min}\right)$ and $0.5 \mathrm{ml}$ of the supernatant was added to potassium phosphate buffer $(0.5 \mathrm{ml})(10 \mathrm{mM}, \mathrm{pH} 7.0)$ and $2 \mathrm{ml}$ of $1 \mathrm{M}$ KI. The absorbance was read at $390 \mathrm{~nm}$, and the HP content was given on a standard curve from 0 to 40 $\mathrm{mM}$. The standard curve equation was $\mathrm{y}=0.0188 \mathrm{x}+$ $0.046, R^{2}=0.987$. HP concentrations were expressed in $\mathrm{nM}$ per gram of fresh weight.
Chlorophylls ( $\mathrm{Ch}$ a and $\mathrm{Ch}$ b) and carotenoids were extracted from fresh plant stems $(100 \mathrm{mg}$ ) using $80 \%$ acetone for $6 \mathrm{~h}$ in darkness, and then centrifuged at $10,000 \mathrm{rpm}, 10 \mathrm{~min}$. Supernatants were quantified spectrophotometrically. Absorbances were determined at 646, 663 and $470 \mathrm{~nm}$ and the equations 2, 3, 4 were used for calculations according to Lichtenthaler and Welburn [31] when $80 \%$ of acetone is used as dissolvent. Total chlorophyll content was calculated as the sum of chlorophyll a and b contents.

$$
\begin{aligned}
& \text { Cha }=\frac{\left(12.21 \times A_{663}\right)-\left(2.81 \times A_{646}\right) \times m l \text { Acetone }}{\text { mg sample }} \\
& \text { Chb }=\frac{\left(20.13 \times A_{646}\right)-\left(2.81 \times A_{663}\right) \times m l \text { Acetone }}{m g \text { sample }} \\
& \text { Carot }=\frac{\left(\left(1000 \times A_{470}\right)-3.27(\text { Cha })-104(\text { Chb })\right) / 227 \times m l \text { Acetone }}{m g \text { sample }}
\end{aligned}
$$

\section{DNA extraction and RAPD analysis}

A complementary genetic analysis was developed as part of an initial attempt to identify the genetic variation patterns among $S$. europaea populations, with a total of 30 individuals of each population 'in situ' in the field sampled. The random amplified polymorphic DNA (RAPD) fingerprint method was applied as it has been reported as the fastest and simplest method for investigating genetic variability patterns. Three random primers were selected for the analysis: K01 (5'-CATTCGAGCC-3'), M02 (5' -ACAACGCCTC-3') and OPB11 (5'-GTAGACCCGT-3') (Operon Technologies Inc.) based on what has been reported in previous studies [28, 36].

DNA was extracted using CTAB protocol from 100 mg of ground frozen tissue with $1 \mathrm{ml}$ of extracted buffer (CTAB-buffer $20 \mathrm{mg} / \mathrm{ml}$, TRIS-HCL $0.1 \mathrm{M} \mathrm{pH} \mathrm{8,} \mathrm{NaCl}$ 1.4 M, EDTA $20 \mathrm{mM} \quad \mathrm{pH} 8$ and $0.5 \% \quad \beta-$ mercaptoethanol). Random amplified polymorphic DNA assays were performed in $25 \mu \mathrm{L}$ total volume containing $2.5 \mu \mathrm{l}$ of buffer (with $1.5 \mathrm{mM}$ final concentration of $\mathrm{MgCl} 2), 0.5 \mu \mathrm{l}$ of $\mathrm{dNTP}(0.2 \mathrm{mM}$ of each dNTP), $0.5 \mu \mathrm{l}$ of primer $(0.1 \mu \mathrm{M})$ and $0.625 \mu \mathrm{l}$ of Taq DNA polymerase (0.65 U) (Eurx, Molecular Biology Products) and $30 \mathrm{ng}$ of DNA. The RAPD-PCR was carried out for 35 cycles consisting of denaturation at $94{ }^{\circ} \mathrm{C}$ for $1 \mathrm{~min}$, annealing at $34{ }^{\circ} \mathrm{C}$ for $1 \mathrm{~min}$, and extension at $72{ }^{\circ} \mathrm{C}$ for $1 \mathrm{~min}$, using an automated thermal cycler. The RAPD fragments were separated by electrophoresis on $1.5 \%$ of agarose and visualised by UV. The bands that commonly appeared in each population are defined as monomorphic bands. Conversely, the bands whose presence or absence varied 
among the plant individuals are considered as polymorphic bands.

\section{Statistical and multivariate analysis}

In order to determine the projection of the effect of salt treatment in plants, a principal component analysis (PCA) was developed using XLSTAT software version 2019.4.1 [52]. For this analysis, twelve variables were used, (projected area A, branch number B, shoot diameter $\mathrm{S}$, height, proline $\mathrm{P}$, hydrogen peroxide $\mathrm{HP}$, chlorophyll a Cha, chlorophyll b Chb, total chlorophyll TC, carotenoids Carot, fractal dimension FD, and total colour difference $\Delta \mathrm{E}$ ), arranged in a matrix with the average values obtained from replicates of each treatment and population. A two-way ANOVA comparing treatments within populations and populations within treatments was conducted for all the results with the Holm-Sidak method using SigmaPlot software version 11.0 [49]. The relationships between variables were performed using a Pearson analysis, while a significance test (Kaisere Meyere Olkin) was performed in order to determine which variables had a significant correlation with each other $(\alpha=0.05)$. Then, a 3D plot was developed using the three principal component factors according to the Kaiser criterion which stated that the factors below the unit are irrelevant. The factorial scores of the PCA from each sample were used to calculate the distance (D) between the two points (populations) under the same treatment $P_{1}=\left(x_{1}, y_{1}, z_{1}\right)$ and $P_{2}=\left(x_{2}, y_{2}, z_{2}\right)$ in 3D space of the PCA (equation 5).

$$
D\left(P_{1}, P_{2}\right)=\sqrt{\left(x_{2}-x_{1}\right)^{2}+\left(y_{2}-y_{1}\right)^{2}+\left(z_{2}-z_{1}\right)^{2}}
$$

Where $\mathrm{x}_{2}, \mathrm{y}_{2}$, and $\mathrm{z}_{2}$ are the three main factorial scores in the PCA corresponding to the evaluated treatment in $\mathrm{I}$ and in C. Distances were used to evaluate and determine in which salt treatment the greatest differences between the populations was recorded.

For RAPD analysis, PAST 4.0 software was used to perform a hierarchical agglomerative cluster analysis with the Jaccard's coefficient as the similarity measure and unweighted pair group method with arithmetic mean (UPGMA) for dendrogram construction [22].

\section{Results}

Fractal dimension as a measure of plant biomass under different salinity levels

This study shows the morphometric characteristics of $S$. europaea plants from two different populations that demonstrated a positive effect under moderate salinities 200 and $400 \mathrm{mM} \mathrm{NaCl}$ for Ciechocinek and 200, 400 and $800 \mathrm{mM} \mathrm{NaCl}$ for Inowrocław, while at the extremes
$(0 \mathrm{mM}$ and $1000 \mathrm{mM})$ a decrease in the plant's biomass was observed. Overall, biomass production was higher in the I population compared to $\mathrm{C}$ (Fig. 1). Fractal dimension (FD) was useful for quantitatively characterising the self-similitude properties of plant architecture, with the maximum value reached at $400 \mathrm{mM}$ for $\mathrm{C}$ and I. However, in population $C$, the $F D$ values clearly showed significant differences between salt treatments. Both populations showed significantly different $F D$ values from treatment 0 to $400 \mathrm{mM}$ where an increase of 4.81 and $3.28 \%$ was observed for $\mathrm{C}$ and I respectively. Moreover, a significant difference was found between the two populations.

\section{Morphometry analysis in salinity treatments}

Each population showed a different behaviour in terms of foliage expansion, which is associated with the significant difference found in the number of branches between both populations within 200 and $400 \mathrm{mM}$ treatment (Fig. 2 a). On the other hand, the projected area and height showed the highest values between 200 and $400 \mathrm{mM}$ of $\mathrm{NaCl}$ in both populations, as shown in Figure $2 \mathrm{c}$ and $\mathrm{d}$. A significant difference was found between the two populations at $1000 \mathrm{mM} \mathrm{NaCl}$ in shoot diameter, height and projected area (Fig 2b,c and d).

\section{Colour analysis for growth assessment}

Colour changes were observed during the assay, and it was interesting that a remarkable difference was observed between plants growing under $0 \mathrm{mM}$ and 1000 $\mathrm{mM}$ (Fig. 3). With regard to the $\mathrm{L}^{*}$ value, the treatments in the range of 0 to $1000 \mathrm{mM}$ of $\mathrm{NaCl}$ increased by $10.91 \%$ in I and by $16.67 \%$ in C. The $\mathrm{a}^{*}$ and $\mathrm{b}^{*}$ values show evidence of a decrease and an increase, respectively, between the different salt treatments. This is reflected in the change of $a^{*}$ and $b^{*}$ values from treatment 0 to $1000 \mathrm{mM}$, with a*decreasing by $66.77 \%$ and $\mathrm{b}^{*}$ increasing by $60.58 \%$ for I, and a* decreasing by $98.19 \%$ and $\mathrm{b}^{*}$ increasing by $97.36 \%$ for $\mathrm{C}$ (Fig. 3a). The $\Delta \mathrm{E}$ value (Fig. $3 \mathrm{~b}$ ) indicates the difference among the samples under $0 \mathrm{mM}$ and under salt treatments. As expected, $\Delta \mathrm{E}$ increased by $70.11 \%$ with salt gradient for I and by $117 \%$ for $C$ in the range of $200 \mathrm{mM}$ to $1000 \mathrm{mM}$. In this sense, the $C$ population showed a higher $\Delta \mathrm{E}$ increase percentage compared to the I population.

\section{Relationships between morphometry, colour and biochemical analysis}

$\mathrm{P}$ showed an increase with salinity gradient (Fig. 4a). The results show that $\mathrm{P}$ was significantly higher in the I population compared to the $\mathrm{C}$ population under salt stress, mainly at 400, 800 and $1000 \mathrm{mM}$. Meanwhile, HP increase is significant only at 800 and $1000 \mathrm{mM} \mathrm{NaCl}$ for population $\mathrm{C}$ and only at $1000 \mathrm{mM} \mathrm{NaCl}$ for 


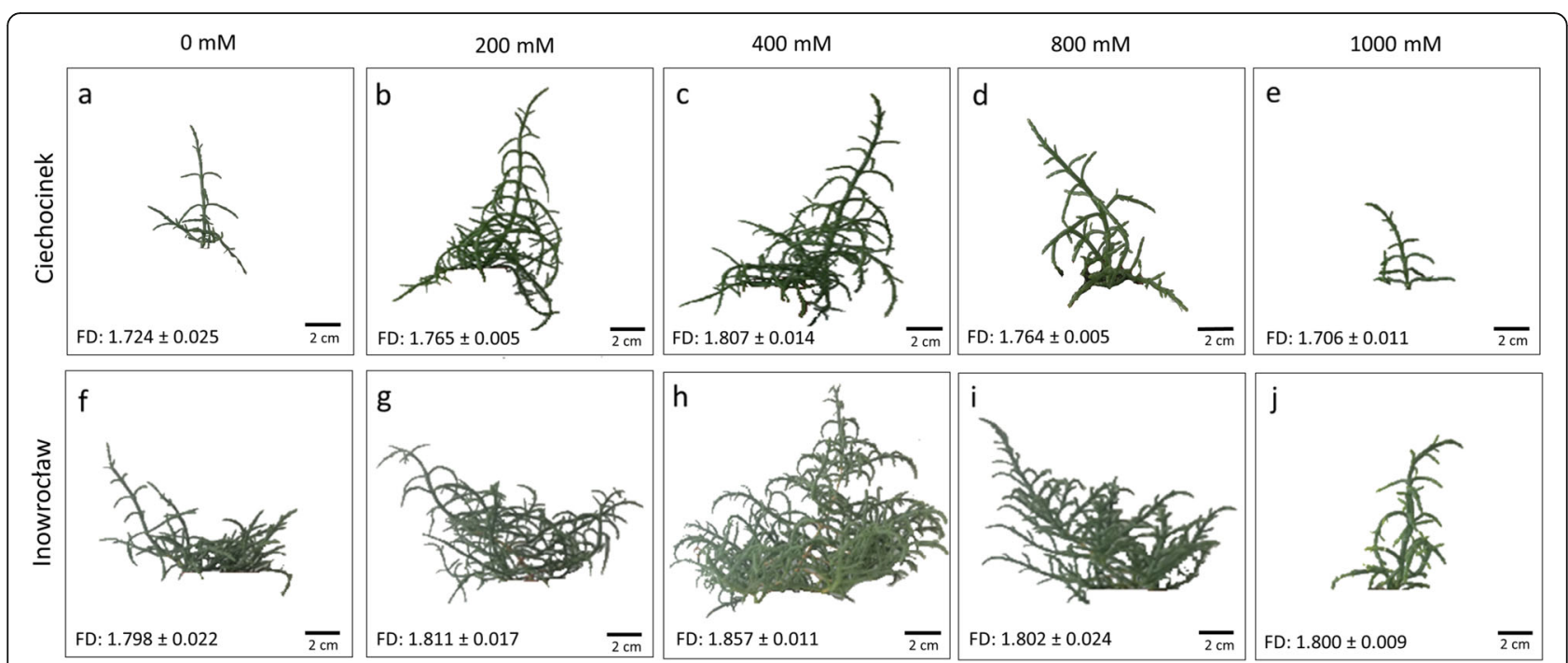

Fig. 1 Growth changes and fractal dimensions after two months in S. europaea, C (a-e) and I (f-j) populations grown under different $\mathrm{NaCl}$ concentrations

population I (Fig. 4b). Chlorophyll a (Ch a), b (Ch b) and carotenoid (Carot), content shows a noteworthy decrease in both populations under $\mathrm{NaCl}$ stress (Fig. 5). The chlorophyll content of both populations was significantly different in $\mathrm{Ch}$ a at $200 \mathrm{mM}$ and in $\mathrm{Ch}$ b at 0 and
$200 \mathrm{mM}$, while there was no significant difference under high salinity (Fig. 5a and b). No significant differences between the two populations were found in total chlorophyll content, but in the case of carotenoid content, significant differences were observed (Fig. $5 \mathrm{c}$ and d).

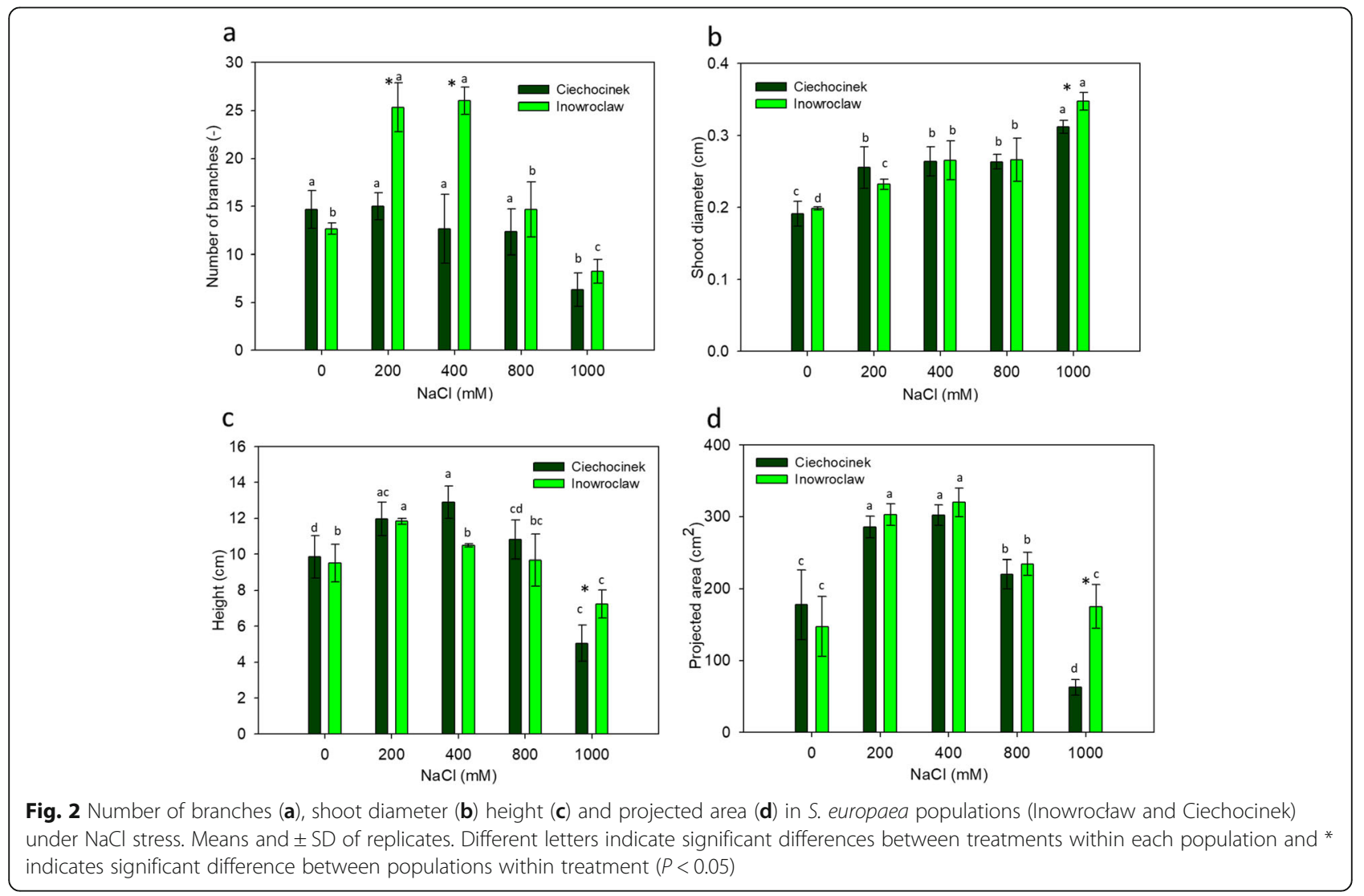




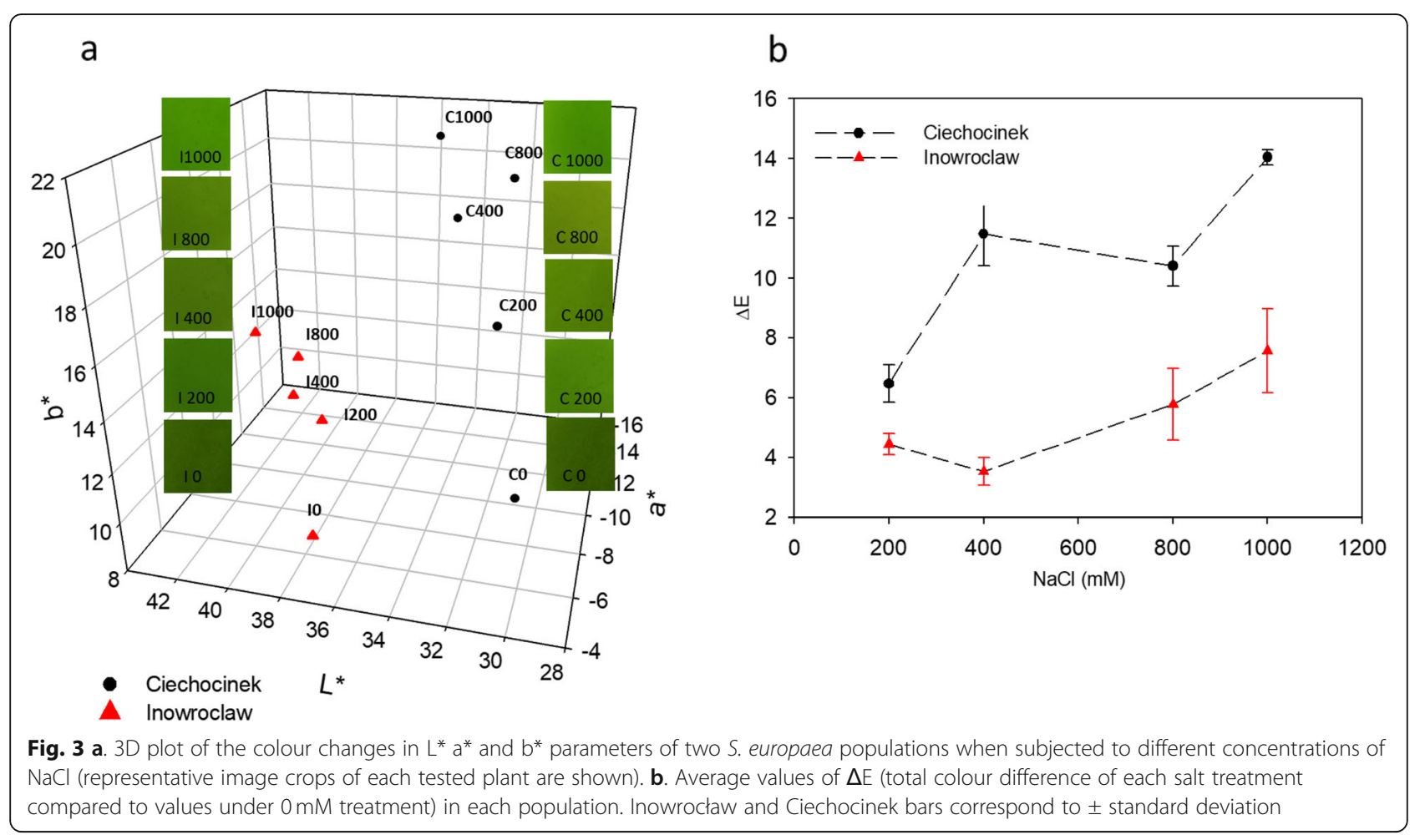

\section{Principal component analysis (PCA) to evaluate the} separation between $S$. europaea populations

All the variables were evaluated in each population using PCA (Fig. 6a). Figure 6a shows the PC1 and PC2 plots which accurately describe the variability of the samples (76.70\%). This plot shows which plants are the most tolerant with regard to saline stress and how they move through the two-dimensional space of the main components, from the negative quadrant of PC1 to the positive quadrant of $\mathrm{PC} 1$ as long as salinity increases. The results were also grouped on a $3 \mathrm{D}$ plot (Fig. 6b) according to their similarities through the three main factor scores (PC1, PC2 and PC3) which describe the variability of the samples $(89.71 \%)$ where C plants are more susceptible to

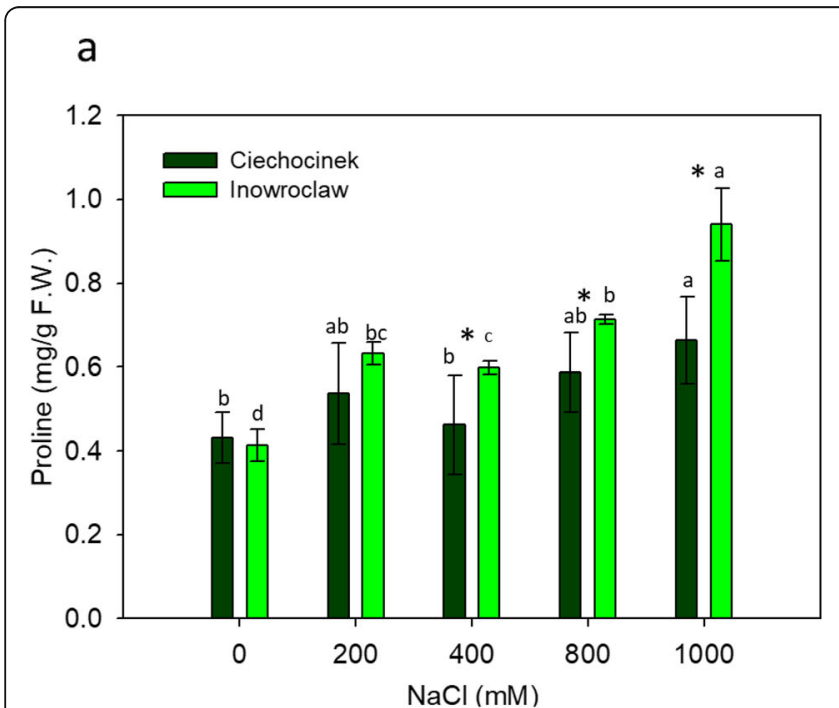

\section{b}

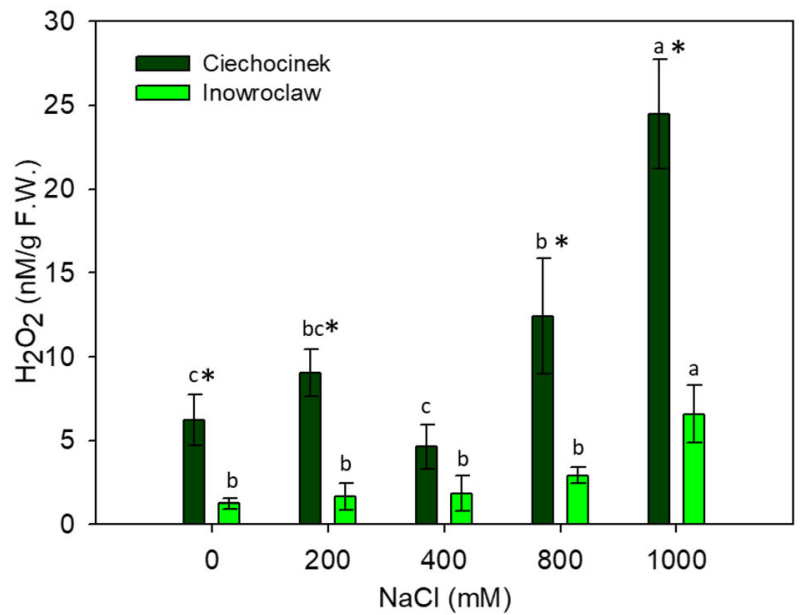

Fig. 4 Contents of proline (a) and $\mathrm{H}_{2} \mathrm{O}_{2}$ (b) in two populations of S. europaea (Inowrocław and Ciechocinek) under $\mathrm{NaCl}$ stress. Means and $\pm \mathrm{SD}$ of replicates. Different letters indicate significant differences between treatments within population and * indicates significant difference between populations within treatment $(P<0.05)$ 

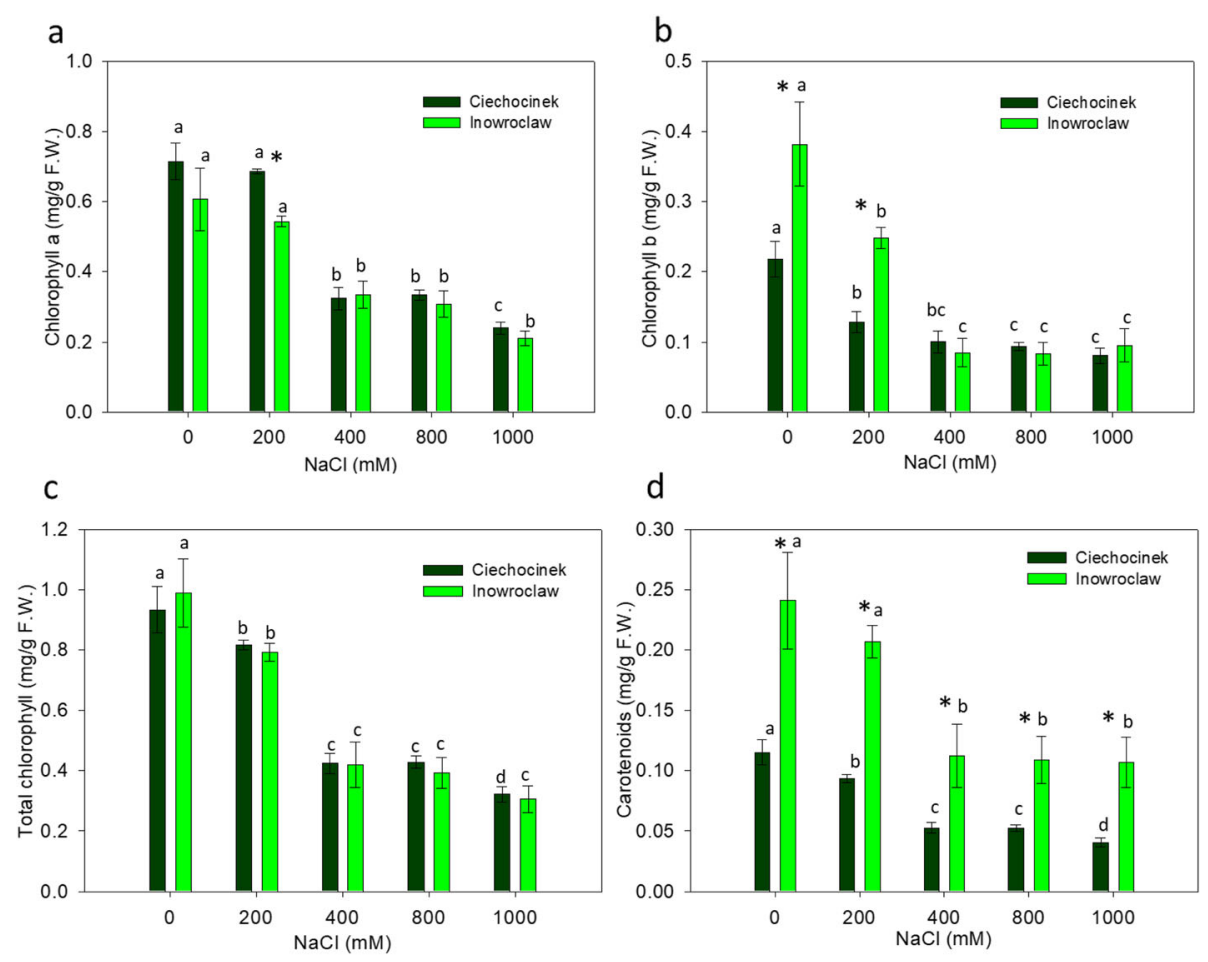

Fig. 5 Chlorophyll a (a), chlorophyll b (b), total chlorophyll (c) and carotenoids (d) contents in S. europaea populations (Inowrocław and Ciechocinek) under $\mathrm{NaCl}$ stress. Means and \pm SD of replicates. Different letters indicate significant differences between treatments within population and * indicates significant difference between populations within treatment $(P<0.05)$

salt stress. Factorial scores from the PCA of each sample were used to calculate the distance between the two points under the same treatment $\mathrm{P} 1=(\times 1, \mathrm{y} 1, \mathrm{z} 1)$ and $\mathrm{P} 2=(\times 2, \mathrm{y} 2, \mathrm{z} 2)$ in the $3 \mathrm{D}$ space of the PCA (Fig. $6 \mathrm{~b})$ for extreme and moderate treatments only $(0,400$ and 1000 $\mathrm{mM}$ ). The comparisons C0 vs I0 (2.49), C400 vs I400 (2.19), and C1000 vs I1000 (3.96) were created in the 3D cartesian axis $(\mathrm{x}=\mathrm{PC} 1, \mathrm{y}=\mathrm{PC} 2, \mathrm{z}=\mathrm{PC} 3)$, with results indicating that the greater the stress, the greater the separation. In addition, a shorter distance is observed at the optimum point $(400 \mathrm{mM})$.

\section{Random amplified polymorphic DNA (RAPD)}

The RAPD analysis of $50 \mathrm{~S}$. europaea plants from two populations with three different primers (K01, M02, OPB11) yielded 15 polymorphic bands. This analysis indicated that the M02 and OPB11 primers have the highest number of polymorphic bands (six), while the K01 primer has the lowest number of polymorphic bands (three). Finally, RAPD analysis shows the relationships between the studied populations which are represented by an unweighted pair group method with an arithmetic mean (UPGMA) dendrogram (Figure 6c). Non-typical bands are present for samples in groups II and III, while group I corresponds to bands solely for C (13 samples out of 28).

\section{Discussion}

The higher FD values correspond to a complex and irregular growth pattern of the plants and therefore to an extensive major branching index as well as an optimisation of the space for optimal growth [5, 15], which results in a mechanism of adaptation to support the stress shown in Figure 1. The FD results obtained are in accordance with those obtained by Karamchedu [25] who studied the foliage of various plants and found that the optimal fractal dimension for photosynthetic efficiency is close to 1.85 in plants, while Bayirli et al. [9] studied the FD in Cercis canadensis L., Robinia pseudoacacia L., Amelanchier arborea (F.Michx.) Fernald, Prunus persica (L.) as well as others, and concluded that the FD with surface density function could be used as a new approach for the taxonomical study of plants. Such measurements give an overall quantitative degree of the growth and fractal architecture of the plants. On the other hand, fractal analysis has shown to be an efficient tool for describing and predicting ecological patterns at multiple scales. Therefore, our results confirm that fractal analysis used as a measure of plant progress was a useful non-destructive tool for a numerical and simple estimate of the biomass and complexity patterns of branched plants [5] which is able to identify different development patterns between two populations. 


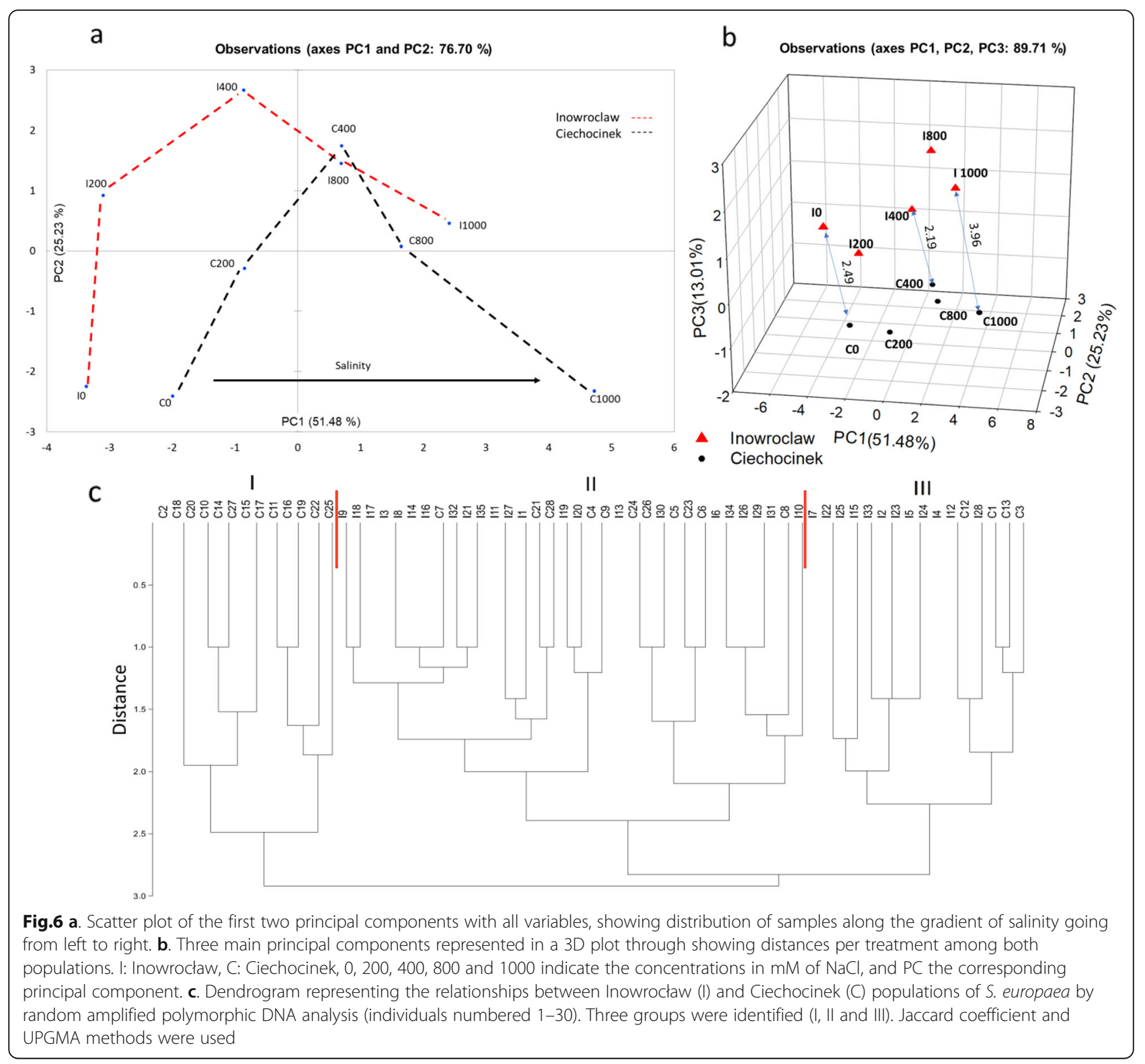

Therefore, FD can be an effective measure of the negative and positive development effects between two populations of S. europaea under different levels of salinity. The I population showed the highest FD values, especially at the highest salinity treatments with a percentage difference of $5.5 \%$, while both populations have the maximum values $(\sim 1.850)$ at $400 \mathrm{mM}$. According to the results obtained with image analysis for morphological evaluation, S. europaea populations appear to have similar behaviour to cope with salinity. However, differences between them are quite visible in each salt treatment such as the height, number of branches, shoot diameter and projected area, which appear higher in the I population, especially at the highest salinity treatment (1000 $\mathrm{mM}$ ). Furthermore, the I population has the highest values for all the morphological parameters tested, where projected area showed the highest difference at approximately $173 \%$. Therefore, image analysis as a nondestructive method is able to identify differences between the two populations under study.

The novelty of this work is the proof that with image analysis it is possible to obtain more precise, accurate and faster results than with visual methods. For instance, it was possible to observe that the shoot diameter in both populations increases with salinity (a detail that would probably be difficult to obtain using a simple view), which means that this value can also be used as an estimative parameter of the amount of salinity present in the environment where the plant is growing. The I shoot diameter was $11.2 \%$ higher than C (Fig. 2 b). 
The morphometric results from this study are in line with those reported by Piernik [43], who, under a field experiment, demonstrated the inferior growth of $S$. europaea at lower salinity $(\sim 20 \mathrm{mM} \mathrm{NaCl})$ than for the home zone $(\sim 200 \mathrm{mM} \mathrm{NaCl})$. The experimental growth optimum for S. europaea was described as $300 \mathrm{mM} \mathrm{NaCl}$ [39] and under field conditions as $38 \mathrm{dS} / \mathrm{m}(\sim 380 \mathrm{mM}$ $\mathrm{NaCl}$ ) [44], which is also reflected by this study's results. Moreover, Szymanska et al. [50] reported differences in situ between the investigated populations. Morphometric parameters were measured by manual inspection with a Vernier calliper and the differences were associated with the environmental conditions and specific microbiomes. Our results prove that under controlled conditions the differences remain the same, even when different salinity levels are taken into account. It is our hypothesis that seeds coming from higher maternal salinity have a genetic makeup in which excessive growth is disadvantageous, although further genetical analysis must be carried out to confirm this hypothesis. ElKeblawy et al. [16] evaluated how the maternal salinity environment affects salt tolerance in Anabasis setifera a desert halophyte. They found significantly less germination and salinity tolerance in the population collected from high-saline habitat than in the non-saline population, they attribute this to a lower vigour of the seeds from saline soil. In comparison with previous studies $[43,50]$, the non-destructive methods provided evidence of the differences in a more efficient and accurate manner.

Colour analysis as a complementary non-destructive method was useful for corroborating that salinity affects the photosynthetic pigment content in S. europaea. The changes in the $\mathrm{L}^{*}$ parameter can be associated with the change from dark green to bright green in the plants due to the lack of chlorophyll. According to certain studies related to colour change [23], $b^{*}$ goes from $+b^{*}$ yellow direction; $\quad b^{*}$ blue direction so higher $b^{*}$ values are associated with high levels of xanthophylls and a loss of chlorophylls in the chloroplasts. In contrast, negative $\mathrm{a}^{*}$ values indicate that the sample is in the green region and positive $\mathrm{a}^{*}$ values indicate that the sample is in the red zone. All these changes are a result of the decrease in the dark greenness of the plants and an increase in light green coloration due to the salinity affecting photosynthetic pigments. The I population has a lower $\Delta \mathrm{E}$ compared to $\mathrm{C}$, with an $85.46 \%$ difference between the two populations in the highest salinity treatment. These results are linked to the chlorophyll and carotenoids analyses which show a decrease with the salinity gradient.

The results indicate that the biosynthesis of pigments in the $\mathrm{C}$ population was more affected by salinity. According to Witzel (2018), $\Delta \mathrm{E}$ values above 5 indicate that the colour difference is perceptible to the human eye, which is an important feature for evaluating phenotypic changes quantitatively through colour image analysis as a non-destructive method. Therefore, our hypothesis that non-destructive methods (FD, image and colour analysis) are able to identify differences between populations subjected to different treatments was proved.

Regarding the proline results, it is already known that proline is an osmotic regulator, enzyme denaturation protector and macromolecule assembly stabiliser that allows additional water to be reserved from the environment. This was observed by an increase in succulence allowing water potentials to decrease [4, 29], and this can be physically observed as shoot thickening through image analysis. Our results are in accordance with studies carried out by Akcin and Yalcin [4], Aghaleh et al. [3] and Aghaleh et al. [2] for S. europaea. The drastic difference in HP content between two populations can be used to corroborate which is more salt-tolerant. According to Kong-ngern et al. [27], salt-tolerant cultivars showed less hydrogen peroxide content compared to salt-sensitive cultivars, with this study indicating that $\mathrm{C}$ is more salt-sensitive when compared to I.

The chlorophyll content of both populations was significantly different at low salinity, while under high salinity there was no significant difference which corroborates our findings obtained through colour analysis. In this sense, it is important to note that Ch b type is an adaptive feature of adapted chloroplasts, while high $\mathrm{Ch} \mathrm{b}$ content produces an increase in the range of wavelengths absorbed by the chloroplasts, which is attributed as a mode of adaptation when plants are subjected to some abiotic stressor [42]. In this study, the I population showed a statistically significant higher $\mathrm{Ch}$ b content compared to population $\mathrm{C}$ under 0 - and 200-mM treatments.

In PCA it is possible to observe that both populations have a similar tendency when they are subjected to different salt treatments, with both demonstrating good adaptation at $400 \mathrm{mM}$ (Table 1). However, the I population seems to cope better with salinity because under $1000 \mathrm{mM}$ it behaves similarly to $\mathrm{C}$ under $800 \mathrm{mM}$, while at $800 \mathrm{mM}$, I behaves similarly to $\mathrm{C}$ at $400 \mathrm{mM}$. This suggests that population I is less affected under high salinity. However, according to Szymańska et al. [50] higher activity of $S$. europaea endophytic microorganisms from the more saline site $(C)$ increases the biomass of roots and a higher density of microbial populations influences differences in morphology of the upper part of the plants, such as shorter length of shoots and the number of first order lateral shoots.

The results of the correlation between investigated parameters are of great interest and some have not been reported before, especially the positive correlation 


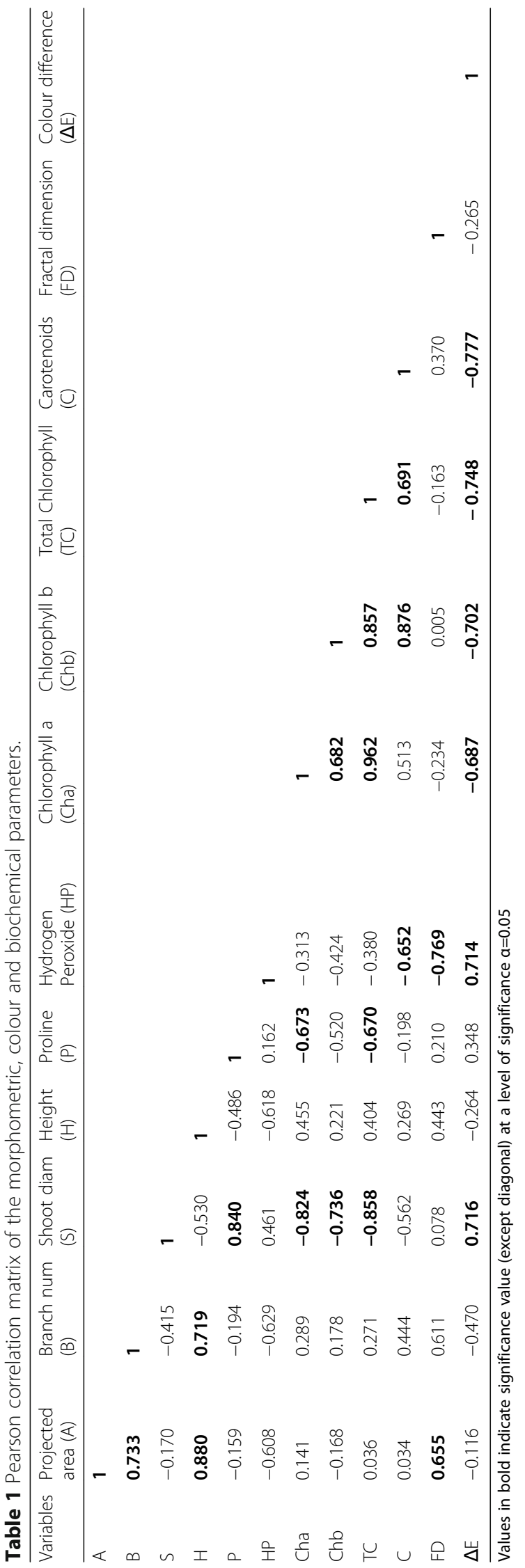


between proline and shoot diameter (0.840) (Table 1). Moreover, the inverse correlation between FD and HP is also an interesting finding, with this result suggesting that when the plant is under salt stress, the HP increases and this is reflected in a reduction in the plant complexity or foliage architecture. In addition, there is a high inverse correlation between the $S$ of the plants (the higher the shoot diameter, the higher the plant succulence) and chlorophyll content (Cha, Chb and TC), which means that succulence is lower when chlorophyll pigments are higher. Plants under high salinity tend to store more water due to a lower stomatal conductance, which leads to an increase in shoot diameter while at the same time decreasing photosynthetic pigments by photoinhibition. Furthermore, $\mathrm{S}$ has a high positive correlation with $\Delta \mathrm{E}$. The biochemical results are in concordance with the morphometric analysis, particularly FD and the colour analysis, which shows that the use of these descriptors is an efficient way of evaluating the growth of plants subjected to saline stress. These descriptors could also be used in the field or in the laboratory as a nondestructive, economic and reliable test which confirms the hypothesis of the work.

Results in Figure 6a allow for the visualisation of population salt tolerance and how both populations move through the bidimensional space, with the advantage being that all the estimated parameters in the PCA are considered. This confirms part of our hypothesis that different populations of the same S. europaea species may adapt to salinity differently. Additionally, factorial scores were useful for demonstrating that the highest separation between I and C parameters was found at the highest salinity, indicating that $\mathrm{C}$ has more modifications at this salinity.

RAPD analysis showed that the population from I has the highest number of polymorphic bands for the three primers K01, OPB11 and M02 with 3, 4 and 5, respectively. Meanwhile, population $\mathrm{C}$ has 2,4 and 4 polymorphic bands for the same primers. This provides evidence of the genetic difference between populations that might be responsible for the different responses to salinity. However, further deep molecular analysis, such as amplified fragment length polymorphism fingerprinting or next-generation sequencing based methods must be performed for a proper genetic variability and analysis of the different gene expressions, because RAPD is now considered a first-approach fingerprint technique.

\section{Conclusions}

This work shows that image analysis was efficient in evaluating salinity-growth response of $S$. europaea as a non-destructive, simple and economical method. Furthermore, FD proved to be a good indicator of the overall foliage development and was able to identify the differences of biomass production between populations and among salt treatments. This non-destructive method is efficient for quantitatively characterising the complexity of plant architecture. The colour analysis was also an efficient method for determining differences between two populations. Moreover, analyzing the shoot diameter through image analysis showed itself to be a good indicator of succulence as well as salinity, both of which would have been very difficult to detect with the naked eye.

The biochemical analysis proved that non-destructive methods provide a sufficient quantity of accurate results without damaging the plant, as confirmed by the Pearson correlation which highlighted the relationships between non-destructive and conventional parameters. PCA provided evidence that the plants from the anthropogenic saline habitat are more tolerant to saline stress. RAPD provided a quick method for determining genetic variation patterns between the two populations which correlates well with the image analysis. Based on our analysis as a whole, it is clear that our applied methods are able to demonstrate that the two $S$. europaea populations do indeed have different mechanisms of salt adaptation, as well as a positive growth effect under moderate salinities. These results can be used in the future for the selection of resistant plants.

The present results obtained with a non-destructive method is novel in the study of salt resistance plants, meaning that researchers can apply these straightforward, low-cost, accurate and fast methods for future experiments related to plant salinity-development responses.

\section{Supplementary information}

Supplementary information accompanies this paper at https://doi.org/10. 1186/s12870-020-02633-8.

Additional file 1. Diagram of image processing for morphometric and colour analysis of S. europaea.

\section{Abbreviations \\ A: Projected area; B: Number of branches; C: Ciechocinek; Carot: Carotenoids; Ch a: Chlorophyll a; Ch b: Chlorophyll b; DNA-RAPD: Random Amplified Polymorphic DNA; FD: Fractal dimension; H: Shoot height; HP: Hydrogen peroxide; I: Inowrocław; P: Proline; PCA: Principal component analysis; ROS: Reactive oxygen species; TC: Total Chlorophyll; S: Shoot diameter; $\Delta \mathrm{E}$ : Colour change}

\section{Acknowledgements}

This research has been supported from research funds provided by the Nicolaus Copernicus Univeristy in Torun, Poland. Also, some financial support provided by CONACYT $(239899,268660)$ and Secretaría de Investigación y Posgrado at IPN (20195198, 20200506) projects, Mexico.

\section{Authors' contributions}

SCP and AP collected soil samples and developed the cultivation process. $\mathrm{AL}, \mathrm{MD}$ and $\mathrm{ASJ}$ contributed to the Random amplified polymorphic DNA analysis experiment. SCP performed all tests. SCP and AP produced the statistical analysis and dendrogram. SCP and JCP developed fractal and 
colour analysis. SCP prepared the manuscript. All authors read and approved the final manuscript.

\section{Funding}

Not applicable.

\section{Availability of data and materials}

The datasets used and/or analysed during the current study are available from the corresponding author on reasonable request.

\section{Ethics approval and consent to participate}

Research was carried out with the permission of Regionalny Dyrektor Ochrony Środowiska w Bydgoszczy, Poland. WPN.6205.159.2014.KLD, WPN.6205.69.2015.KLD, and WPN.6205.44.2016.KLD, correspond to the permission for the Ciechocinek soil samples according to national guidelines. In the case of Inowrocław soil samples, permission was not required because this is a soda factory region.

\section{Consent for publication}

Not applicable.

\section{Competing interests}

The authors declare that they have no competing interest.

\section{Author details}

${ }^{1}$ Chair of Geobotany and Landscape Planning, Faculty of Biological and Veterinary Sciences, Nicolaus Copernicus University, Lwowska 1, 87-100 Toruń, Poland. ${ }^{2}$ Chair of Plant Physiology and Biotechnology, Faculty of Biological and Veterinary Sciences, Nicolaus Copernicus University, Lwowska 1, 87-100 Toruń, Poland. 'Departamento de Ingeniería Bioquímica, Escuela Nacional de Ciencias Biológicas, Instituto Politécnico Nacional, Av. Wilfrido Massieu, Esq. Manuel L. Stampa s/n, 07738, Gustavo A. Madero, Ciudad de México, Mexico.

Received: 19 May 2020 Accepted: 30 August 2020

Published online: 12 October 2020

\section{References}

1. Abraham E, Hourton-Cabassa C, Erdei L, Szabados L. Method for determination of proline in plants. In: Walker JM, editor. Methods in Molecular Biology: Springer; 2010. p. 317-31.

2. Aghaleh M, Niknam V, Ebrahimzadeh $H$, Razavi K. Salt stress effects on growth, pigments, proteins and lipid peroxidation in Salicornia persica and S. europaea. Biol Plant. 2009:53(2):243-8.

3. Aghaleh M, Niknam V, Ebrahimzadeh H, And Razavi K. Antioxidative enzymes in two in vitro cultured Salicornia species in response to increasing salinity. Biol Plant 2014; 58(2):391-394.

4. Akcin A, Yalcin E. Effect of salinity stress on chlorophyll, carotenoid content, and proline in Salicornia prostrata pall. And Suaeda prostrata pall. Subsp. prostrata (Amaranthaceae). Braz J Bot. 2016;39:101-6.

5. Alados CL, Escos J, Emlen JM, Freeman DC. Characterization of branch complexity by fractal analyses. Int J Plant Sci. 1999;160(Suppl):S147-55.

6. Ashraf M. Some important physiological selection criteria for salt tolerance in plants. Flora Morphol Distrib Funct Ecol Plants. 2004;199:361-76.

7. Azlah MAF, Chua LS, Rahmad FR, Abdullah FI, SRW A. Review on techniques for plant leaf classification and recognition. Computers. 2019;8:4

8. Bates LS, Walderd RP, Teare ID. Rapid determination of free pro- line for water stress studies. Plant Soil. 1973;39:205-8.

9. Bayirli M, Selvi S, Cakilcioglu U. Determining different plant leaves fractal dimensions: a new approach to taxonomical study of plants. Bangladesh J Botany. 2014:43(3):275-83.

10. Benjamin JJ, Miras-Moreno B, Araniti F, Salehi H, Bernardo L, Parida A, Lucini L. Proteomics Revealed Distinct Responses to Salinity between the Halophytes Suaeda maritima (L.) Dumort and Salicornia brachiata (Roxb). Plants. 2020;9:227

11. Boudon F, Chopard J, Ali O, Gilles B, Hamant O, Boudaoud A, Traas J, Godin C. A computational framework for 3D mechanical modelling of plant morphogenesis with cellular resolution. PLoS Comput Biol. 2015:11: e1003950.

12. Camacho-Díaz BH, Aparicio AJ, Chanona-Pérez JJ, Calderón-Domínguez G, Alamilla-Beltrán L, Hernández-Sánchez H, Gutiérrez-López GF. Morphological characterization of the growing front of Rhizopus oligosporus in solid media. J Food Eng. 2010;101(3):309-17.

13. Cárdenas-Pérez S, Chanona-Pérez JJ, Méndez-Méndez JV, CalderónDomínguez G, López-Santiago R, Arzate-Vázquez I. Nanoindentation study on apple tissue and isolated cells by atomic force microscopy, image and fractal analysis. Innov Food Sci Emerg Technol. 2016;34:234-42.

14. Cárdenas-Pérez S, Chanona-Pérez J, Méndez-Méndez JV, CalderónDomínguez G, López-Santiago R, Perea-Flores MJ, Arzate-Vázquez I. Evaluation of the ripening stages of apple (Golden delicious) by means of computer vision system. Biosyst Eng. 2017;159:46-58.

15. Corbit JD, Garbary DJ. Fractal dimension as a quantitative measure of complexity in plant development. Proc Biol Sci. 1995;262(1363):1-6.

16. El-Keblawy A, Gairola S, Bhatt A. Maternal salinity environment affects salt tolerance during germination in Anabasis setifera: a facultative desert halophyte. J Arid Land. 2016:8(2):254-63.

17. Food and Agriculture Organization of the United Nations, Available at: http://www.fao.org/soils-portal/soil-management [accessed November 2019].

18. Gage JL, Miller ND, Spalding EP, Kaeppler SM, de Leon N. TIPS: a system for automated image-based phenotyping of maize tassels. Plant Methods. 2017; 13(1):1-12.

19. Golzarian MR, Frick RA, Rajendran K, Berger B, Roy S, Tester M, Lun DS. Accurate inference of shoot biomass from high-throughput images of cereal plants. Plant Methods. 2011;7:2.

20. Grattan SR, Benes SE, Peters DW, Diaz F. Feasibility of irrigating pickleweed (Salicornia bigelovii. Torr) with hyper-saline drainage water. J Environ Qual. 2008;37:S149-56.

21. Hairmansis A, Berger B, Tester M, Roy SJ. Image-based phenotyping for non-destructive screening of different salinity tolerance traits in rice. Rice. 2014;7:16

22. Hammer $\varnothing$, Harper DAT, Ryan PD. PAST: paleontological statistics software package for education and data analysis. Palaeontol Electron. 2001:4(1):1-9.

23. Itle RA, Kabelka EA. Correlation between lab color space values and carotenoid content in pumpkins and squash (Cucurbita spp.). Hortic Sci. 2009;44(3):633-7.

24. Jansen M, Pinto F, Nagel KA, Dusschoten D, Fiorani F, Rascher U, Schneider HU, Walter A, Schurr U. Non-invasive phenotyping methodologies enable the accurate characterization of growth and performance of shoots and roots. In: Tuberosa R, Graner A, Frison E, editors. Genomics of plant genetic resources. Dordecht: Springer Netherlands; 2014. p. 173-206.

25. Karamchedu CD. Use of fractal dimension ratios of plant images as an allometric predictor of plant biomass. Jesuit high school, Portland, OR USA. IEEE Int Geosci Remote Sensing Symp (IGARSS). 2016.

26. Karcher DE, Richardson MD. Turfgrass science. Crop Sci. 2003;43:943-51.

27. Kong-ngern K, Bunnag S, Theerakulpisut P. Proline, hydrogen peroxide, membrane stability and antioxidant enzyme activity as potential indicators for salt tolerance in rice (Oryza sativa L.). Int J Bot. 2012:8(2):54-65.

28. Krüger AM, Hellwig FH, Oberprieler C. Genetic diversity in natural and antropogenic inland populations of salt-tolerant plants: random amplified polymorphic DNA analysis of Aster tripolium L. (Compositae) and Salicornia ramosissima woods (Chenopodiaceae). Mol Ecol. 2002:11:1647-55.

29. Kumar A, Bandhu A. Effects of $\mathrm{NaCl}$ stress on nitrogen and phosphorous metabolism in a true mangrove Bruguiera parviflora grown under hydroponic culture. Plant Sci. 2004;161:921-8.

30. Le Marié C, Kirchgessner N, Marschall D, Walter A, Hund A. Rhizoslides: paper-based growth system for non-destructive, high throughput phenotyping of root development by means of image analysis. Plant Methods. 2014;10(1):1-16.

31. Lichtenthaler $\mathrm{H}$, Wellburm AR. Determination of total carotenoids and chlorophyll a and b of leaf extracts in different solvents. Biochem Soc Trans. 1983:603:591-3.

32. Lien MR, Barker RJ, Ye Z, Westphall MH, Gao R, Singh A, Gilroy S, Townsend PA. A low-cost and open-source platform for automated imaging. Plant Methods. 2019:15(1):1-14.

33. Lv S, Jiang $P$, Chen $X$, Fan P, Wang X, Li Y. Multiple compartmentalization of sodium conferred salt tolerance in Salicornia europaea. Plant Physiol Biochem. 2012;51:47-52.

34. Ma L, Fang J, Chen Y, Gong S. Color analysis of leaf images of deficiencies and excess nitrogen content in soybean leaves. In Proceedings of the 2010 International conference on E-product E-service and E-entertainment, Henan, China, vol. 11541023; 2010. p. 1-3. 7-9 November. 
35. Mendoza F, Aguilera JM. Application of image analysis for classification of ripening bananas. J Food Sci. 2004;69(9):471-7.

36. Milić D, Luković J, Dan M, Zorić L, Obreht D, Veselić S, Anačkov G, Petanidou T. Identification of Salicornia population: anatomical characterization and RAPD fingerprinting. Arch Biol Sci. 2011;63:4.

37. Mishra A, Patel MK, Jha B. Non-targeted metabolomics and scavenging activity of reactive oxygen species reveal the potential of Salicornia brachiata as a functional food. J Funct Foods. 2015;13:21-31.

38. Moriuchi KS, Friesen ML, Cordeiro MA, Badri M, Vu WT, Main BJ, Aouani M, Nuzhdin S, Strauss S, Von Wettberg EJB. Salinity adaptation and the contribution of parental environmental effects in medicago truncatula. PLoS One. 2016;11(3):1-19.

39. Muscolo A, Panuccio MR, Piernik A. Ecology, distribution and ecophysiology of Salicornia europaea L. In: Khan MA, Böer B, Öztürk M, Al Abdessalaam TZ, Clüsener-Godt M, Gul B (eds) Sabkha ecosystems. Volume IV: Cash Crop Halophyte and Biodiversity Conservation, Tasks for Vegetation Science 47. Netherlands: Springer; 2014. p. 233-40.

40. Negrao S, Schmo SM. Evaluating physiological responses of plants to salinity stress, 1-11. Ann Bot. 2017:119:1-11.

41. Nelson M, Mareida M. Environmental impacts of the CGIAR: an assessment, in Doc. No. Durban: SDR presented to the Mid-Term Meeting; 2001.

42. Papageorgiou CG, Stamatakis K. In: Papageorgiou G, Govindjee C, editors. Water and solute transport in cyanobacteria as probed by chlorophyll fluorescence, in Chlorophyll a Fluorescence: A Signature of Photosynthesis. Dordrecht: Springer; 2004. p. 663-78.

43. Piernik A. Growth of three meadow species along a salinity gradient in an inland saline habitat: transplant experiment. Pol J Ecol. 2006:117-25.

44. Piernik A. Ecological pattern of inland salt marsh vegetation in Central Europe. Torun: NCU Press; 2012.

45. Piernik A, Kaźmierczak E, Rutkowski L. Differenciation of vegetation in a saline grassland in the vicinity of Inowrocław soda plants at Mątwy. Acta Soc Bot Pol. 1996;65:349-56.

46. Piernik A, Hrynkiewicz K, Wojciechowska A, Szymańska S, Lis Ml, Muscolo A. Effect of halotolerant endophytic bacteria isolated from Salicornia europaea $\mathrm{L}$. on the growth of fodder beet (Beta vulgaris L.) under salt stress. Arch Agron Soil Sci. 2017:63:1404-18.

47. Piernik A, Hulisz P, Rokicka A. Micropattern of halophytic vegetation on technogenic soils affected by the soda industry. Soil Sci Plant Nutr. 2015;61: 98-112.

48. Singh D, Yadav NS, Tiwari V, Agarwal PK, Jha B. A SNARE-like superfamily protein SbSLSP from the halophyte Salicornia brachiata confers salt and drought tolerance by maintaining membrane stability, $\mathrm{K}(+) / \mathrm{Na}(+)$ ratio, and antioxidant machinery. Front Plant Sci. 2016;7:737.

49. SigmaPlot Version 11 n.d.. Systat Software, Inc., San Jose California USA, www.systatsoftware.com.

50. Szymańska S, Piernik A, Baum C, Złoch M, Hrynkiewicz K. Metabolic profiles of microorganisms associated with the halophyte Salicornia europaea in soils with different levels of salinity. Ecoscience. 2014;21(2):114-22.

51. Velikova V, Yordanov I, Edreva A. Oxidative stress and some antioxidant systems in acid rain-treated bean plants. Protective role of exogenous polyamines. Plant Sci. 2000;151:59-66.

52. XLSTAT Version 2019.4.1 Copyright Addinsoft 1995-2019 (2019) XLSTAT and Addinsoft are Registered Trademarks of Addinsoft.https://www.xlstat.com.

\section{Publisher's Note}

Springer Nature remains neutral with regard to jurisdictional claims in published maps and institutional affiliations.

Ready to submit your research? Choose BMC and benefit from:
- fast, convenient online submission
- thorough peer review by experienced researchers in your field
- rapid publication on acceptance
- support for research data, including large and complex data types
- gold Open Access which fosters wider collaboration and increased citations
- maximum visibility for your research: over 100M website views per year
At BMC, research is always in progress.
Learn more biomedcentral.com/submissions

